Abstracta Iranica Abstracta Iranica

Revue bibliographique pour le domaine irano-aryen

Volume 32-33 | 2013

Comptes rendus des publications de 2009-2010

\title{
Kazuya Yamauchi, Shin-ichi Nishyama. Chapter 11. Archaeological Survey in the Bolaghi Valley and Its Vicinity
}

\section{Rémy Boucharlat}

\section{(2) OpenEdition \\ 1 Journals}

\section{Édition électronique}

URL : http://journals.openedition.org/abstractairanica/40443

DOI : 10.4000/abstractairanica.40443

ISSN : 1961-960X

Éditeur :

CNRS (UMR 7528 Mondes iraniens et indiens), Éditions de l'IFRI

\section{Édition imprimée}

Date de publication : 1 décembre 2013

ISSN : 0240-8910

Référence électronique

Rémy Boucharlat, "Kazuya Yamauchi, Shin-ichi Nishyama. Chapter 17. Archaeological Survey in the Bolaghi Valley and Its Vicinity ", Abstracta Iranica [En ligne], Volume 32-33 | 2013, document 132, mis en ligne le 01 juillet 2016, consulté le 05 octobre 2020. URL : http://journals.openedition.org/ abstractairanica/40443 ; DOI : https://doi.org/10.4000/abstractairanica.40443

Ce document a été généré automatiquement le 5 octobre 2020.

Tous droits réservés 


\title{
Kazuya Yamauchi, Shin-ichi Nishyama. Chapter 11. Archaeological Survey in the Bolaghi Valley and Its Vicinity
}

\author{
Rémy Boucharlat
}

\section{RÉFÉRENCE}

Kazuya Yamauchi, Shin-ichi Nishyama. «Chapter 11. Archaeological Survey in the Bolaghi Valley and Its Vicinity ", in : A. Tsuneki and M. Zeidi, eds., Tang-i Bolaghi. The Iran-Japan Archaeological Project for the Sivand Dam Salvage Area. Iranian Center for Archaological Research and Department of Archaeology, University of Tsukuba, 2008, p. 170-252. (Al Shark 3, University of Tsukuba, Studies in West Asian Archaeology)

1 Dans le cadre du projet international de fouilles de sauvetage dans la vallée de Bolaghi, qui s'ouvre à $2 \mathrm{~km}$ au sud du tombeau de Cyrus à Pasargades (2005-2007), la mission conjointe irano-japonaise s'est principalement intéressé à la préhistoire et l'ouvrage

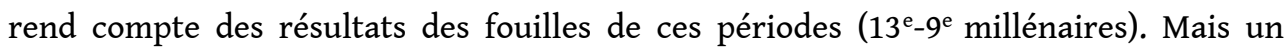
niveau, pauvre en matériel, est attribué à l'époque achéménide (chap. 7, p. 124-131). Plus important pour cette période, la prospection d'ensemble de la vallée ainsi que de la plaine de Pasargades révèle un système complexe de canaux, particulièrement identifiables lorsqu'ils sont creusés dans la roche, parfois au prix d'un travail impressionnant, ce qu'avait mentionné E. Herzfeld jadis, et partiellement étudié D. Stronach dans son Pasargadae (1978), p. 166-167. Comme ce dernier, les auteurs japonais reconnaissent dans plusieurs de ces entailles rupestres une route, parfois seulement des canaux, dans d'autres constructions des éléments de murs, tous ces éléments étant probablement de l'époque achéménide. Tout cela est indiqué par des tracés de couleurs différentes portés sur des images satellite QuickBird. Pour la mission française, qui a également travaillé sur ces vestiges, ces traces - entailles rupestres et 
murs parallèles à la vallée - appartiennent à deux systèmes de canaux qui couraient de chaque côté de la rivière depuis l'entrée de la gorge atteignant presque l'extrémité en aval de la vallée, que ferme maintenant le barrage moderne. Pour une autre interprétation des murs, voir l'hypothèse de M. Atai (Abs. Ir. 30, c.r. $\left.n^{\circ} 54\right)$.

\section{AUTEURS}

\section{RÉMY BOUCHARLAT}

CNRS, Lyon 